\title{
A dupla excepcionalidade altas habilidades/superdotação associada ao transtorno do espectro autista: compreendendo as especificidades
}

\section{The dual exceptionality high abilities/giftedness associated with autism spectrum disorder: understanding the specifics}

\author{
Jailson Araujo Cipriano ${ }^{1 *}$, Lívia da Conceição Costa Zaqueu ${ }^{1}$
}

\begin{abstract}
RESUMO
Este artigo científico teve como objetivo produzir um Estado da Arte sobre a temática da Dupla Excepcionalidade (D.E) em pessoas com altas habilidades com transtorno do espectro autista nível 1. Tratase de uma pesquisa bibliográfica, qualitativa e de cunho exploratório. Foi utilizada a técnica de análise de conteúdo de Bardin (2011) para a análise de dados. À luz dos autores até aqui estudados podemos verificar que dos 09 (nove) artigos, 05 (cinco) deles são de revisão e 04 (quatro) são de pesquisa aplicada, o que coaduna com a literatura que aponta a necessidade de mais pesquisas aplicadas sobre o assunto. Foram analisados nove artigos segundo critérios preestabelecidos. As características mais presentes de maior incidente apontadas pelos autores foram: fraca capacidade de interação social, dificuldade de ser empático foco intenso naquilo em que lhes interessam e assincronia entre o desenvolvimento cognitivo motor e o Desenvolvimento Social e afetivo.
\end{abstract}

Palavras-chave: Dupla Excepcionalidade; Transtorno do Espectro Autista nível 1; Altas Habilidades/Superdotação; Estado da Arte; Educação Especial e Inclusiva.

\section{ABSTRACT}

This scientific article aimed to produce a State of the Art on the theme of Double Exceptionality (D.E) in people with high abilities with level 1 autistic spectrum disorder. It is characterized as a bibliographical, qualitative and exploratory research. Bardin's (2011) content analysis technique was used for data analysis. In the light of the authors studied so far, we can see that of the 09 (nine) articles, 05 (five) of them are review and 04 (four) are applied research, which is consistent with the literature that points to the need for more applied research on the subject. Nine articles were analyzed according to pre-established criteria. The most present characteristics of the greatest incident pointed out by the authors were: weak capacity for social interaction, difficulty in being empathic, intense focus on what they are interested in, and asynchrony between motor cognitive development and social and affective development.

Keywords: Double Exceptionality; Level 1 Autistic Spectrum Disorder; High Abilities/Giftness; State of art; Special and Inclusive Education.

\footnotetext{
${ }^{1}$ UFMA - Universidade Federal do Maranhão

*E-mail: cipriano.jailson@ discente.ufma.br
} 


\section{INTRODUÇÃO}

Este artigo científico do tipo revisão teve como objetivo produzir um Estado do Conhecimento sobre a temática da Dupla Excepcionalidade (D.E) em pessoas com altas habilidades com transtorno do espectro autista nível 1.

A dupla excepcionalidade, pode ser compreendida pela existência de alto desempenho em uma área, como: talentos artísticos, esportivos, acadêmicos, relacionados a um transtorno, um distúrbio ou até mesmo uma deficiência. Nestes casos, a literatura especializada, aponta a existência de uma dupla condição especial na qual um indivíduo manifesta Altas Habilidades/Superdotação conjuntamente com Transtorno do Espectro Autista, ou com o Déficit de Atenção e Hiperatividade (TDAH), ou conjuntamente com a surdez, ou associada à dislexia, ou à cegueira, além de outras condições/deficiências (MASSUDA; RANGNI, 2017).

De modo geral uma criança com altas habilidades/superdotação pode ter uma grande quantidade de conhecimento em algumas áreas, e em outras, não ter pontos fortes, e apresentar até algumas dificuldades de aprendizagem em algumas das matérias estudadas. Embora pareça um fenômeno paradoxal, a dupla excepcionalidade que envolve o fenômeno da superdotação associada ao TEA nível 1, é uma condição que requer melhores e mais aprofundados estudos, e maior envolvimento de equipes multidisciplinares e interdisciplinares para que se evitem juízos distorcidos e prematuros, pois o não adequado entendimento sobre esse fenômeno, acarreta prejuízos para seus possuidores, além de reforçar a exclusão social (VILARINHO-REZENDE, FLEITH; ALENCAR, 2016).

A falta de Políticas Públicas direcionadas ao atendimento de estudantes com dupla excepcionalidade poderá trazer resultados drásticos para estes estudantes, tais como: desmotivação, isolamento social e abandono escolar. E é em favor dessa minoria da população, negligenciada, muitas vezes excluída e mantida invisível, enquadrada na grande categoria da Educação Especial, que nos propomos a pesquisar (OUROFINO; FLEITH; GONÇALVES, 2011).

Vários autores denunciam que pouco se tem dado atenção para pesquisas sobre o assunto devido ainda haver poucas produções acadêmicas e científicas sobre esta temática em foco, e que a maioria das produções são de revisão, tendo uma necessidade de maior 
investimento em pesquisas aplicadas (VIEIRA E SIMON, 2012; GUIMARÃES; ALENCAR, 2012; MASSUDA; RANGNI, 2017).

Frente às questões levantadas até aqui, surgiu a indagação que nos leva automaticamente à questão central deste trabalho: Que tipos de assuntos são recorrentes nas produções acadêmicas (artigos em periódicos indexados) sobre a temática da dupla excepcionalidade com transtorno do espectro autista nível 1 ?

Para responder à questão central, elencamos duas hipóteses que procurarão dar suporte à pesquisa: a primeira é que as produções destes artigos tratam das características comuns dos possuidores do fenômeno em pauta e, a segunda é que elas dão algumas orientações sobre como lidar com o fenômeno em estudo, e isto produz um maior aporte aos professores de Educação Especial e também aos docentes da classe comum para lidarem com estes estudantes.

A partir da divulgação dessa pesquisa do tipo Estado da Arte, espera-se que outros pesquisadores despertem interesse pela temática, vindo com isso a formar uma massa crítica de investigadores sobre o assunto. Esperamos também com este trabalho, contribuir com os docentes da Educação Básica da escola comum, sobre a temática da dupla excepcionalidade.

\section{METODOLOGIA}

Os acervos pesquisados nas bibliotecas eletrônicas e plataformas Google Acadêmico, Researchgate e o Scientific Eletronic Library Online - SciELO formaram o lastro para nosso Estado da Arte. Utilizou-se um recorte temporal que contempla uma abrangência dos anos de 2012 a 2021. Arrolamos o termo Dupla excepcionalidade em um primeiro momento e conseguimos o retorno de 136 artigos nas três plataformas. Em seguida acrescentamos os termos dupla condição e dupla necessidade educativa especial e encontramos 146 artigos. Retiramos aqueles trabalhos que se voltavam para a área jurídica e ficaram apenas 89 (oitenta e nove).

Neste terceiro refinamento escolhemos apenas os artigos em periódicos em língua portuguesa e que fosse totalmente construído sobre o teor da dupla excepcionalidade no campo do Transtorno do Espectro Autista com Altas Habilidades. Foram selecionados apenas 9 (nove) trabalhos, sendo 2 (dois) da SciELO, 4 (quatro) do Google Acadêmico e 3 (três) da Researchgate. Os artigos foram lidos e resumidos nos meses de maio a 
setembro de 2021, e serviram para melhor compreensão sobre o fenômeno da dupla excepcionalidade no contexto da Educação Especial e Inclusiva e para a construção do Estado da Arte. Segundo Ferreira (2002, p. 257) as investigações nomeadas de Estado da Arte visam a revisão das produções científicas e trazem o "desafio de mapear e de discutir uma certa produção acadêmica em diferentes campos do conhecimento".

Silva e Carvalho afirmam que:

O estado da arte é um método de pesquisa que se realiza por meio de uma revisão bibliográfica sobre a produção de determinada temática em uma área de conhecimento específica. Essa revisão busca identificar que teorias estão sendo construídas, quais procedimentos de pesquisa são empregados para essa construção (SILVA E CARVALHO, 2014, p. 348).

Utilizamos como critério de inclusão que os artigos, necessariamente, fossem publicados em periódicos em Língua Portuguesa, além de abordar sobre a temática da dupla excepcionalidade na perspectiva da educação especial e inclusiva e que fossem totalmente voltados para o fenômeno do transtorno do espectro autista com altas habilidades. Acrescentamos as expressões dupla condição e dupla necessidade educativa especial. Passaremos a discorrer sobre os artigos na sequência em que se apresentam em cada quadro e em suas respectivas bases de dados. No quadro 1 podemos ver os artigos catalogados a partir da SciELO:

Quadro 1 - Artigos catalogados por meio da plataforma SciELO

\begin{tabular}{|c|c|c|c|c|c|c|}
\hline & Autor & Título & Ano & Natureza & Periódico & Descritores \\
\hline 1 & $\begin{array}{l}\text { VILARINHO- } \\
\text { REZENDE, } \\
\text { Daniela; } \\
\text { FLEITH, } \\
\text { Denise de } \\
\text { Souza; } \\
\text { ALENCAR, } \\
\text { Eunice Maria } \\
\text { Lima Soriano } \\
\text { de. }\end{array}$ & $\begin{array}{l}\text { Desafios no diagnóstico de } \\
\text { dupla excepcionalidade: } \\
\text { um estudo de caso }\end{array}$ & 2016 & $\begin{array}{l}\text { Pesquisa } \\
\text { Aplicada }\end{array}$ & $\begin{array}{l}\text { Revista de } \\
\text { Psicologia, } \\
\text { Campinas, v. } \\
\text { 34, n. 1,. p. } \\
\text { 61-84. jan.- } \\
\text { jun. 2016. }\end{array}$ & $\begin{array}{l}\text { Dupla } \\
\text { excepcionalidade, } \\
\text { superdotação, } \\
\text { síndrome de } \\
\text { Asperger, estudo } \\
\text { de caso. }\end{array}$ \\
\hline 2 & $\begin{array}{l}\text { SILVA, Sarah } \\
\text { Carolina } \\
\text { Furucho; } \\
\text { RANGNI; } \\
\text { Rosemeire de } \\
\text { Araújo }\end{array}$ & $\begin{array}{l}\text { Indicadores de altas } \\
\text { habilidades superdotação } \\
\text { em aluno com síndrome de } \\
\text { asperger: estudo de caso. }\end{array}$ & 2019 & $\begin{array}{l}\text { Pesquisa } \\
\text { Aplicada }\end{array}$ & $\begin{array}{l}\text { EccoS } \\
\text { January } 2020 \\
\text { Revista } \\
\text { Científica } \\
\text { DOI: } \\
\text { 10.5585/eccos. } \\
\text { n51.8334 }\end{array}$ & $\begin{array}{l}\text { Educação } \\
\text { Especial; Altas } \\
\text { Habilidades/Super } \\
\text { dotação; } \\
\text { Síndrome de } \\
\text { Asperger; Dupla } \\
\text { Excepcionalidade; } \\
\text { Identificação. }\end{array}$ \\
\hline
\end{tabular}

Fonte: CIPRIANO; ZAQUEU (2021) 
O primeiro artigo "Desafios no diagnóstico da dupla excepcionalidade: um “estudo de caso" Vilarinho-Rezende, Fleith, Alencar (2016), apresenta um estudo de caso de uma criança superdotada que estava em processo de diagnóstico da Síndrome de Asperger. Foram realizadas entrevistas com a criança, com a mãe e com os profissionais que a acompanhavam. Foram analisadas as avaliações psicológicas, neurológica e fonoaudiológica junto ao estudante. Percebem-se dificuldades no processo de identificação. Portanto, deve ser dada uma maior valorização ao trabalho multidisciplinar sobre o fenômeno da dupla excepcionalidade - Transtorno do Espectro Autista com Altas Habilidades.

Em suas pesquisas, as autoras afirmam que nos últimos dez anos houve um aumento de realizações de identificação e diagnósticos de crianças com alguma deficiência, porém precisa ser dada atenção maior aos casos de dupla excepcionalidade e recomendam que os profissionais conheçam profundamente sobre ambos os fenômenos. Descrevem as características de estudantes com a dupla excepcionalidade, o que, às vezes, confundem-se - estas crianças, de forma concomitante, apresentam as características do transtorno do espectro autista nível leve, e as características das altas habilidades, como por exemplo: podem resistir à mudança de rotina; em ambo os casos, possuem hiperfoco, apresentam assincronismos, certas dificuldades motoras como desajeitamentos, e podem apresentar também dificuldades no processamento verbal, além de algumas dificuldades sociais e comunicacionais.

No artigo de Silva e Rangni (2019) "Indicadores de altas habilidades superdotação em estudante com síndrome de asperger: estudo de caso" as autoras pesquisaram sobre indicadores de altas habilidades em uma criança diagnosticada com síndrome de Asperger, e como objetivo, propuseram verificar se a professora de arte do estudante, seu responsável e o próprio estudante reconheciam os seus próprios potenciais artísticos.

As autoras afirmam que crianças com dupla excepcionalidade são aquelas que gostam de ler livros e desenvolvem habilidades de leitura de modo autônomo, contudo, elas podem apresentar dificuldades em situações inusitadas. Costumeiramente, essas crianças se encontram na categoria criativo-produtivo. Afirmam que crianças apresentam alta performance, talento habilidade, e potencial, ocorrendo em conjunto com uma desordem psiquiátrica, educacional, sensorial e física. Elas afirmam que, na maioria dos casos, as crianças com dupla excepcionalidade são deixadas de fora dos programas de educação especial para estudantes com altas habilidades por apresentarem algumas 
dificuldades, já citadas anteriormente. Também afirmam que a análise, no caso deste fenômeno, deve ser feita com um olhar multidisciplinar e que não é fácil a obtenção desse diagnóstico.

Silva e Rangni (2019) afirmam que os professores e os colegas dele, participantes do estudo de caso, disseram que quando o estudante pesquisado não gosta da disciplina e dos conteúdos, é taxado como aquele que fica no "mundo da lua". Algumas vezes gosta de fazer os trabalhos de sozinho, muitas vezes em particular, não em grupo. Apresenta um pouco de perfeccionismo e grande curiosidade sobre assuntos incomuns, diferentemente dos seus demais colegas. Nas relações sociais, o estudante tende se isolar, apresentando prejuízos nas interações sociais, apesar de ter elevados potenciais.

No quadro 2 podemos ver os artigos catalogados a partir do agregador Google Acadêmico:

Quadro 2 - Artigos catalogados por meio do agregador Google Acadêmico

\begin{tabular}{|c|c|c|c|c|c|c|}
\hline & Autor & Título & Ano & Natureza & Periódico & Descritores \\
\hline 1 & $\begin{array}{l}\text { GUIMARÃES, Tânia } \\
\text { Gonzaga e ALENCAR, } \\
\text { Eunice M. L. Soriano de. }\end{array}$ & $\begin{array}{l}\text { Dupla } \\
\text { excepcionalidade } \\
\text { superdotação e } \\
\text { transtorno de } \\
\text { Asperger: } \\
\text { contribuições } \\
\text { teóricas }\end{array}$ & 2012 & $\begin{array}{l}\text { Artigo de } \\
\text { Revisão }\end{array}$ & $\begin{array}{l}\text { Revista } \\
\text { AMAzônica } \\
\text {, UFAM } \\
\text { Ano 5, Vol } \\
\text { X, no 3, pág. } \\
95-108 \text {, Jul- } \\
\text { Dez 2012 } \\
\text { (Extra). }\end{array}$ & $\begin{array}{l}\text { Dupla } \\
\text { excepcionalid } \\
\text { ade; } \\
\text { Superdotação; } \\
\text { Transtorno de } \\
\text { Asperger. }\end{array}$ \\
\hline 2 & $\begin{array}{ll}\text { RAMOS, } & \text { Sheila } \\
\text { Debastiani; } & \\
\text { HERNANDEZ, } & \text { Aline } \\
\text { Calvo. } & \end{array}$ & $\begin{array}{l}\text { Dilemas em } \\
\text { educação inclusiva: } \\
\text { problematizações } \\
\text { em torno às crianças } \\
\text { com altas } \\
\text { habilidades/Asperg } \\
\text { er. }\end{array}$ & 2019 & $\begin{array}{l}\text { Pesquisa } \\
\text { Aplicada }\end{array}$ & $\begin{array}{l}\text { Rev. } \\
\text { Educação } \\
\text { Artes e } \\
\text { Inclusão, V. } \\
\text { 15, n. 01, } \\
\text { Jan./Mar. } \\
\text { 2019 } \\
\end{array}$ & $\begin{array}{l}\text { Educação. } \\
\text { Dupla } \\
\text { necessidade } \\
\text { educacional. } \\
\text { Altas } \\
\text { habilidades. } \\
\text { Asperger. } \\
\end{array}$ \\
\hline 3 & $\begin{array}{ll}\text { SOARES, Larissa de } \\
\text { Sousa; } & \text { OLIVEIRA, } \\
\text { Geane Silva. }\end{array}$ & $\begin{array}{l}\text { Síndrome de } \\
\text { Asperger: } \\
\text { manifestações } \\
\text { clínicas e sua } \\
\text { relação com a dupla } \\
\text { excepcionalidade }\end{array}$ & 2020 & $\begin{array}{l}\text { Artigo de } \\
\text { Revisão }\end{array}$ & $\begin{array}{l}\text { Revista } \\
\text { interdiscipli } \\
\text { nar em } \\
\text { saúde } \\
\text { Cajazeiras, } \\
\text { ano } 7 / 2020 \\
\text { Paraíba -PB, } \\
\text { p. 551-562. }\end{array}$ & $\begin{array}{l}\text { Síndrome de } \\
\text { Asperger; } \\
\text { Inteligência; } \\
\text { Sinais e } \\
\text { Sintomas. }\end{array}$ \\
\hline 4 & $\begin{array}{l}\text { COUTINHO-SOUTO, } \\
\text { Waleska Karinne Soares } \\
\text { e FLEITH, Denise de } \\
\text { Souza }\end{array}$ & $\begin{array}{l}\text { Inclusão } \\
\text { educacional: estudo } \\
\text { de caso de um aluno } \\
\text { com dupla } \\
\text { excepcionalidade }\end{array}$ & 2021 & $\begin{array}{l}\text { Pesquisa } \\
\text { Aplicada }\end{array}$ & $\begin{array}{l}\text { Revista de } \\
\text { Psicologia, } \\
\text { Vol. } 39 \text { (1), } \\
2021, \quad \text { pp. } \\
339-381\end{array}$ & $\begin{array}{l}\text { inclusão } \\
\text { educacional, } \\
\text { dupla } \\
\text { excepcionalid } \\
\text { ade, } \\
\text { superdotação, } \\
\text { transtorno de } \\
\text { Asperger }\end{array}$ \\
\hline
\end{tabular}

Fonte: CIPRIANO; ZAQUEU (2021). 
O artigo "Dupla excepcionalidade, superdotação e Transtorno de Asperger: contribuições teóricas" de Guimarães e Alencar (2012) inicia com a denúncia da escassez da literatura sobre a temática, especialmente na abordagem deste tema. Estas autoras estudam os traços comuns e os discrepantes presentes na dupla excepcionalidade. No artigo acima citado, os autores arrolam os traços comuns entre os indivíduos que apresentam dupla excepcionalidade: fluência verbal, excelente memória, interesse por letras e números e prazer em memorizar, grande interesse em um tópico específico, vasto repertório de informações sobre o tópico que os fascina, hipersensibilidade a estímulos sensoriais como a ruídos, toques, textura e sabor de alimentos, inclusive com algumas iluminações e cores, assincronia entre desenvolvimento cognitivo e o desenvolvimento social e afetivo, excelente desempenho em algumas áreas e mediana em outras por misturarem ambas qualidades às características do transtorno de Asperger e das altas habilidades.

De acordo com o estudo realizado pelos autores acima, as pessoas com dupla excepcionalidade podem demonstrar dificuldades de entender a perspectiva do outro, podem apresentar boa criatividade, podem apresentar desequilíbrios emocionais como ansiedade e distúrbio de choro. Muitas vezes falam muito sobre um tema preferido sem se preocupar se o interlocutor está interessado ou não em ouvi-los.

Como achados de conclusão Guimarães e Alencar (2012), apresentam que é importante haver mais estudos empíricos e aprofundados, para suprir as carências sobre esta temática. Isto contribuirá muito para a vida escolar desses indivíduos e das famílias. É fundamental que os profissionais que trabalham na área atuem de forma coletiva, multiprofissional, com avaliação médica, psicológica e que se estude as características cognitivas, sociais, emocionais, comportamentais e neuropsicológicas, além de exames profundos para que não causem erros nos diagnósticos.

O artigo de Ramos e Hernandez (2019) “Dilemas em educação inclusiva: em torno as crianças com altas habilidades e Asperger” é uma pesquisa aplicada em que se utilizou como descritores educação, dupla necessidade educacional, altas habilidades, Asperger.

A pesquisa realizada por Ramos e Hernandez (2019) possui abordagem qualitativa do tipo exploratória descritiva para discutir a questão da dupla excepcionalidade em pessoas que manifestam altas habilidades conjuntamente com transtorno de Asperger. O objetivo do trabalho foi discutir métodos de ensino para obtenção de atendimento às crianças com altas habilidades, e visa auxiliar professores 
que trabalham nessa área. Denunciam que, muitas vezes estes estudantes acabam esquecidos nas suas necessidades intelectuais, afetivas, emocionais, sociais e comunicacionais, e que não há espaço também nas políticas públicas para curso de formação docente voltado para o fenômeno em questão.

As autoras citadas acima elencaram quatro Campos de Análise: o primeiro deles “desacordos e polêmica entre Altos habilidosos e aspergers afirmam que, muitas vezes, o transtorno mascara ou dificulta o diagnóstico da dupla excepcionalidade, porque essas pessoas, algumas vezes, se apresentam com raciocínio um pouco mais lento, tendo dificuldades de fazer alguns links com outras posições abstratas de uma situação para outra. Muitas vezes, o possuidor do fenômeno apresenta assincronia, se isola, e frequentemente não entende metáforas, por conta do comprometimento, tendo dificuldade de entender linguagens figuradas, apesar de ter memórias preservadas.

Na segunda categoria, "problematização em torno de diagnósticos" as autoras apresentam que é um desafio para as categorias médicas e educacionais trabalharem em conjunto, e conjuntamente analisar os problemas e as dificuldades de aprendizagem e os déficits motivacionais, além de outros.

Na terceira categoria "avaliação de progressão em pessoas com dupla necessidade educacional" as entrevistadas falam que, muitas vezes, devido à falta de um bom método educacional, sem diversificação pedagógica, repetições e mesmices, as crianças perdem a motivação e o interesse pelo processo ensino e aprendizagem.

$\mathrm{Na}$ última categoria "trajetórias escolares de pessoas com altas habilidades e superdotação", afirmam que muitas vezes as crianças sofrem bullying e é preciso que haja acompanhamento psicológico, e que frequentemente os professores só focam mais nas dificuldades destas crianças, em vez de focar também nas habilidades e em suas capacidades.

Portanto, em seus achados finais as autoras afirmam que se se deflagre programas de formações continuadas para os professores, com a finalidade de que eles aprendam a fazer a escuta profissional e educacional, recebendo melhor preparo. Também alertam que a família participe mais, pela aproximação com a escola, para que estes estudantes recebam melhor acompanhamento em Atendimento Educacional Especializado.

O próximo artigo analisado foi o de Soares e Oliveira (2020), intitulado "Síndrome de Aspeger: manifestações clínicas e sua relação com a dupla excepcionalidade". Este teve como objetivo realizar uma revisão integrativa da literatura 
no intuito de conhecer as manifestações clínicas apresentadas na síndrome de Asperger, bem como na relação desse quadro com a dupla excepcionalidade. Soares e Oliveira (2020), apresentam que a síndrome de Asperger se encaixa no transtorno do espectro autista nível leve, e que as pessoas afetadas possuem dificuldades de interação social e dificuldades de serem empáticas. Os duplos excepcionais não são atingidos com comprometimentos intelectuais, sua capacidade intelectiva é preservada.

As autoras falam que os estudantes que têm dupla excepcionalidade apresentam boa capacidade linguística, contudo apresentam dificuldade de comunicação e socialização; comprometimento na capacidade de compreender e transmitir significados.

Como conclusão, Soares e Oliveira (2020) afirmam que nos casos de dupla excepcionalidade essas pessoas possuem intelecto preservado, acima da média ou na média, podem conversar fluentemente, têm dificuldade em ser empáticos em suas relações sociais; possuem humor preservado, muito embora não compreendam expressões utilizadas em piadas e têm dificuldades em fazer amizades com indivíduos do mesmo sexo e mais jovens.

Existe uma grande dificuldade de diagnóstico, porque as peculiaridades de cada particularidade se entrelaçam e muitas vezes fica difícil de se diagnosticar. É indispensável o apoio da família e a assistência de profissionais especializados. Deve-se prestar atenção para se evitar pressões exacerbadas sobre esses indivíduos, pois isto causa aumento de níveis de estresse e compromete seus esforços e seu sucesso.

O artigo, "Inclusão Educacional: estudo de caso de um aluno com dupla excepcionalidade de Coutinho-Souto e Fleith (2021) teve como objetivo um estudo de caso, analisando a inclusão educacional de um estudante superdotado com transtorno de Asperger, a partir da perspectiva dos gestores, professores, mãe e do próprio estudante. O estudo revela a importância da formação de professores como um dos pilares básicos para que haja práticas pedagógicas inclusivas. Denuncia a ausência de estudos empíricos nesta área do conhecimento. Aborda sobre a importância e atuar com a complementação para o transtorno do espectro autista e a suplementação para as altas habilidades,

O estudo elenca alguns fatores que contribuíram para a inclusão educacional de estudantes com a dupla excepcionalidade, como por exemplo: a participação da gestão escolar; frequência no atendimento educacional especializado; a identificação precoce da dupla excepcionalidade; o fato dos professores terem boa noção do assunto e saberem trabalhar com eles; a participação da família e da escola dando apoio na vida ativa do 
estudante, atendendo às suas necessidades emocionais e o próprio estudante apresentando um autoconceito positivo de si mesmo.

As autoras também pontuam alguns desafios na inclusão desse processo educacional como: a própria interação social limitada do estudante; algumas dificuldades emocionais; a assincronia entre o desenvolvimento cognitivo e o psicomotor.

As autoras destacam que o atendimento educacional valorizou as potencialidades do estudante em pauta e focou nos seus pontos fortes, e isso contribuiu também para o aumento de sua autoestima e de autoconhecimento e focaram também na socialização e na empatia. As autoras apelam para que todos devam estar incluídos nesse processo, gestores, professores, pais e coordenação pedagógica para conhecerem sobre o assunto.

No quadro abaixo, podemos verificar os artigos indexados na ReseachGate:

Quadro 3 - Artigos Catalogados por meio da plataforma Researchgate

\begin{tabular}{|c|c|c|c|c|c|c|}
\hline & Autor (es) & Título/subtítulo & Ano & Natureza & Periódico & Descritores \\
\hline 1 & $\begin{array}{l}\text { VIEIRA, Nara Joyce } \\
\text { Wellausen; SIMON, } \\
\text { Karolina Waechter. }\end{array}$ & $\begin{array}{l}\text { Diferenças } \\
\text { semelhanças na } \\
\text { dupla necessidade } \\
\text { educacional } \\
\text { especial: altas } \\
\text { habilidades/superdo } \\
\text { tação x Síndrome de } \\
\text { Asperger. }\end{array}$ & 2012 & $\begin{array}{l}\text { Artigo de } \\
\text { Revisão }\end{array}$ & $\begin{array}{l}\text { Revista } \\
\text { Educação } \\
\text { Especial, } \\
\text { Santa Maria, } \\
\text { v. 25, n. 43, } \\
\text { p. 319-332, } \\
\text { maio/ago. } \\
\text { 2012.. }\end{array}$ & $\begin{array}{l}\text { Altas } \\
\text { habilidades/su } \\
\text { perdotação; } \\
\text { Síndrome de } \\
\text { Asperger; } \\
\text { Dupla } \\
\text { necessidade } \\
\text { educacional } \\
\text { especial. }\end{array}$ \\
\hline 2 & $\begin{array}{l}\text { SIMÕES, } \\
\text { PEREIRA, } \quad \text { Marcelino; } \\
\text { OLIVEIRA, Guiomar. }\end{array}$ & $\begin{array}{l}\text { Síndrome de } \\
\text { Asperger } \\
\text { Sobredotação } \\
\text { Intelectual: análise } \\
\text { diferencial }\end{array}$ & 2013 & $\begin{array}{l}\text { Artigo de } \\
\text { Revisão }\end{array}$ & $\begin{array}{l}\text { Article } \\
\text { October } \\
2013 \text { Aneis. } \\
\text { v. } 13\end{array}$ & $\begin{array}{l}\text { Sobredotação } \\
\text { intelectual. } \\
\text { Síndrome de } \\
\text { Asperger. } \\
\text { Análise } \\
\text { diferencial }\end{array}$ \\
\hline 3 & $\begin{array}{l}\text { ALVES, Rauni Jandé } \\
\text { Roama; NAKANO, } \\
\text { Tatiana de Cássia. }\end{array}$ & $\begin{array}{l}\text { A dupla- } \\
\text { excepcionalidade: } \\
\text { relações entre altas } \\
\text { habilidades/superdo } \\
\text { tação com a } \\
\text { síndrome de } \\
\text { Asperger, } \\
\text { transtorno de } \\
\text { déficit de atenção e } \\
\text { hiperatividade e } \\
\text { transtornos de } \\
\text { aprendizagem. }\end{array}$ & 2015 & $\begin{array}{l}\text { Artigo de } \\
\text { Revisão }\end{array}$ & $\begin{array}{l}\text { Revista } \\
\text { Psicopedago } \\
\text { gia - ABPp, } \\
\text { São Paulo - } \\
\text { SP.; v.10 } \\
\text { (99):346- } \\
\text { 360, 2015. }\end{array}$ & $\begin{array}{l}\text { Inteligência. } \\
\text { Criatividade. } \\
\text { Síndrome de } \\
\text { Asperger. } \\
\text { Transtorno } \\
\text { do deficit de } \\
\text { atenção com } \\
\text { hiperatividade. } \\
\text { Transtornos de } \\
\text { aprendizagem. }\end{array}$ \\
\hline
\end{tabular}

Fonte: CIPRIANO; ZAQUEU (2021).

No artigo de Vieira e Simom "Diferenças e semelhanças na dupla necessidade educacional especial: altas habilidades/superdotação x Síndrome de Asperger” (2012), estudo este de revisão sistemática, e discutem elementos como: concepções sobre altas 
habilidades e Asperger (incluso na nova configuração, no DSM- 5 como TEA nível 1) e como se apresentam a criatividade e o desempenho intelectual de ambos as situações. Também apresentam os aspectos comunicacionais e comportamentais dos possuidores deste fenômeno com fragilidades ou lacunas.

Enfatizam que durante o diagnóstico, é importante verificar a regularidade e a expressividade, além da consistência com que os comportamentos e as habilidades de superdotação aparecem nos repertórios desses indivíduos, o que implica que deve haver uma continuidade dessas características, não podendo ser apenas algo espasmódico ou intermitente, pois para efeitos de diagnósticos elas devem aparecer de forma frequente, constante e cotidiana nesses indivíduos.

As autoras Vieira e Simon (2012), destacam quatro categorias para destacar as similaridades e diferenças entre as altas habilidades e o TEA nível 1. São elas: cognição, interação social, comunicação e comporta $\mathrm{s}$, mento adaptativo (restritivos e estereotipados). Estas afirmam ser a cognição uma característica relativa à memória, e em ambas as necessidades educacionais especiaios indivíduos apresentam destaque por evidenciarem excelente memória. Outra característica cognitiva apresentada pelas mesmas é que, em ambas as necessidades educacionais especiais, as pessoas com dupla excepcionalidade possuem uma boa oralidade, podendo apresentar precocidade em leitura como habilidade cognitiva e linguagem sofisticada, além de apresentarem um elevado Quociente Intelectual (Q.I).

Sobre a segunda categoria, a interação social, asseveram que os Aspergers possuem dificuldades de se colocarem no lugar de outros, não possuem comportamentos de empatia em seu discernimento de distinguir entre ficção e realidade e possuem dificuldades em fazer novas amizades e um certo desinteresse em participar da vida em comunidade, o que não é observado nas altas habilidades/superdotação, principalmente quando eles são do tipo líder.

$\mathrm{Na}$ categoria comunicação, essas pessoas apresentam dificuldades em começar uma conversa ou mantê-la. Afirmam que os estudantes com Asperger possuem discursos pedantes, cheios de sons e de pronuncias exageradas, situações estas que não são apresentadas em pessoas com altas habilidades/superdotação, por terem apenas um discurso normal e até mais rebuscado, sem ser pedante.

Por último as autoras abordam a quarta categoria denominada comportamento adaptativo. As pessoas com a síndrome de Asperger apresentam algumas sensibilidades 
a sons, principalmente aos agudos e os de maior intensidade, apresentando às vezes comportamentos restritos e estereotipados, o que por outro lado não ocorrem os mesmos sintomas com pessoas com altas habilidades/superdotação. Na conclusão as autoras afirmam que há pouca produção científica sobre a temática e conclamam para que haja mais pesquisas sobre o assunto.

No artigo de Simões, Pereira, e Oliveira, "Síndrome de Asperger e Sobredotação Intelectual: análise diferencial" (2013), estes abordam alguns aspectos da sobredotação intelectual e a síndrome de Asperger. Os autores declaram que existem subgrupos de sobredotação dentro da categoria dupla excepcionalidade. Afirmam que alguns autores chegam a asseverar que o fato de uma pessoa ter altas habilidades, ser talentosa e ao mesmo tempo apresentar dificuldades, se torna até um paradoxo chegando a causar dificuldades na identificação e até na intervenção psicopedagógica correta. Portanto, é necessário um trabalho de melhor identificação para que ocorram intervenções pedagógicas de boa qualidade.

Os estudantes com dupla excepcionalidade necessitam de serviços de apoio, tanto especial nas áreas relacionadas a sua sobredotação, quanto de igual modo aos seus níveis de dificuldades diagnosticadas. Além disso, esta população precisa de atendimento que trabalhe as questões psicossociais juntamente com a família, envolvendo uma série de procedimentos que, apesar de tentar superar os aspectos negativos, neles presentes, foquem mais seus potenciais.

Simões, Pereira e Oliveira (2013) mostram que, muitas vezes, essas crianças mantém um elevado foco nos objetivos específicos de um pensamento superior aos demais colegas, porém apresentam dificuldades como a ansiedade, e, no entanto, possuem uma capacidade excepcional, em nível de memória. Muitas vezes, elas são precoces verbalmente, e possuem um vocabulário com boa fluência, muito embora sejam isoladas e introvertidas. Denunciam também haver pouca investigação empírica neste campo. Afirmam que o ideal é que este fenômeno seja detectado aos 3 anos de idade para um melhor acompanhamento (SIMÕES; PEREIRA; OLIVEIRA, 2013).

Apresentam também desenvolvimento assíncrono de vários níveis cognitivos e socioemocionais, sendo isso também um fato que muitas vezes também aparece nos indivíduos apenas sobredotados, no entanto, as pessoas que têm apenas transtorno do espectro autista, têm mais acentuadamente problemas de comportamentos adaptativos nos aspectos social e comunicacional, todavia por meio de uma análise diferencial, que os 
autores se propõem, o indivíduo pode carregar ambos os traços (SIMÕES; PEREIRA; OLIVEIRA, 2013).

Eles possuem forte capacidade de concentração e aprendem facilmente as coisas nos domínios que tem interesse. Frequentemente, os duplos excepcionais com transtorno de Asperger apresentam pouca consciência dos seus sentimentos, e compreensão das necessidades de outrem, e se distraem mais facilmente. Os mesmos tendem a ter maior isolamento social, e déficit no campo socioemocional (SIMÕES; PEREIRA; OLIVEIRA, 2013).

Sobre o artigo de Alves e Nakano (2015), intitulado "A dupla-excepcionalidade: relações entre altas habilidades/superdotação com a síndrome de Asperger, transtorno de déficit de atenção e hiperatividade e transtornos de aprendizagem", nos limitamos a reproduzir as falas dos autores restritos aos aspectos que dizem respeito somente ao objeto de estudo de nossa pesquisa. Os autores, começam o artigo conceituando a dupla excepcionalidade como aquele fenômeno em que há presença de alta performance, talento, habilidade ou potencial, ocorrendo em conjunto com uma desordem psiquiátrica, educacional, sensorial e física.

Alves e Nakano (2015) apresentam aspectos de ambas as condições: altas habilidades com a síndrome de Asperger, como fatores vistos como negativos que podem apresentar prejuízo na interação social; desenvolvimento de padrões restritos e repetitivos de comportamento, interesses e atividades. Apresentam algumas outras dificuldades como as de aprendizagem, algumas dificuldades quanto a mudanças de rotina, dificuldades de contato visual, ausência de compreensão de raciocínio abstrato, pois consideram tudo no sentido literal, ou seja, entendem tudo de forma denotativa, apresentando igualmente, algumas estereotipias e complicações, especialmente no campo das atividades motoras finas.

Nos assuntos que tratam de contato social, os estudantes que apresentam síndrome de Asperger apenas podem exprimir dificuldades, enquanto os que possuem altas habilidades/superdotação não manifestam dificuldades de socialização; os que tem síndrome de Asperger podem falar incessantemente sobre determinado assunto, tema de seu interesse, sem perceber a reação do outro.

As pessoas com dupla excepcionalidde, apesar de apresentarem algumas dificuldades socioemocionais, geralmente possuem inteligência superior e habilidades 
superiores em diferentes áreas. Em se tratando de comportamento social, este foi "um dos indicadores mais marcantes e importante de ser investigado mais detalhadamente.

\section{DISCUSSÕES E RESULTADOS}

À luz dos autores até aqui estudados podemos verificar que dos 09 (nove) artigos, 05 (cinco) deles são de revisão e 04 (quatro) são de pesquisa aplicada o que coaduna com a literatura que aponta a necessidade de mais pesquisas aplicadas sobre o assunto. Os anos 2012 e 2019 foram os que mais apresentaram produções sobre a temática, dois artigos em cada um deles. Fruto da leitura à luz da técnica de Análise de Conteúdo de Bardin (2011), podemos elencar as principais características, a saber:

A primeira característica com maior nível de incidência de abordagem é a fraca capacidade de interação social pontuadas pelos autores Guimarães e Alencar (2012) Vieira e Simon (2012), Simões, Pereira e Oliveira (2013), Alves e Nakano (2015), Soares e Oliveira (2020) e Coutinho-Souto e Fleith (2021) que se manifestam, por exemplo em preferirem realizar atividades sozinhos e não em grupos.

A segunda característica mais propalada foi a fraca empatia ou dificuldade de ser empático pontuadas pelos autores Guimarães e Alencar (2012), Vieira e Simon (2012), Alves e Nakano (2015), Soares e Oliveira (2020) que se traduz pela dificuldade de se colocar em lugar do outro e de entender o ponto de vista deles.

Na sequência, a terceira característica, o hiperfoco ou foco intenso naquilo que eles especificamente se interessam, as ilhas de competências ou centros de interesse, pontuada pelos autores Vilarinho-Rezende, Fleith, Alencar (2016), Coutinho-Souto e Fleith (2021), sendo esta característica uma das principais formas que os diferencia dos demais.

No mesmo nível da variável hiperfoco, a quarta característica é a assincronia entre o desenvolvimento cognitivo, motor, psicomotor e o desenvolvimento social e afetivo apresentada pelos autores Simões, Pereira e Oliveira (2013), Vilarinho-Rezende, Fleith, Alencar (2016) e Ramos e Hernandez (2019). Geralmente o desenvolvimento cognitivo apresenta-se acima da média em contrapartida de um descompasso entre este e o desenvolvimento social, por exemplo.

A próxima característica, a quinta, é a memória cognitiva preservada e na maioria das vezes acima da média, pontuados pelos autores Guimarães e Alencar (2012), Ramos 
e Hernandez (2019), Soares e Oliveira (2020). O fato de um estudante ter altas habilidades com a presença do transtorno do espectro autista leve, não é motivo para apresentar-se com baixa cognição.

A próxima característica, fraca capacidade comunicacional, apontada pelos autores Vilarinho-Rezende, Fleith, Alencar (2016), Ramos e Hernandez (2019) e Soares e Oliveira (2020), em que se demonstra em dificuldades de iniciar e manter conversação e entender emoções e sentimentos dos outros. Apresentam-se com dificuldades de entenderem linguagem figurada, bem como dificuldade em distinguir entre ficção e realidade.

Dentro do fenômeno da dupla excepcionalidade há alguns aspectos relevantes que são levantados em discussão pelos autores aqui elencados e que merecem salientar-se como: a falta de políticas públicas que assegurem a formação continuada de qualidade para que se atuem com propriedade e eficácia neste contexto; a falta de instrumentos apropriados para diagnósticos de duplo excepcionais; a escassez de trabalhos empíricos nesta área do conhecimento; a importância de um diagnóstico e intervenções precoces para maior aproveitamento e desenvolvimento do estudante; importância da participação, envolvimento e compromisso da família no acompanhamento pedagógico do estudante.

Abordam também sobre a importância da diversificação de métodos de ensino. Estudantes com dupla excepcionalidades não gostam da mesmice de aulas repetitivas, podendo perder o interesse e tornar-se impacientes com a ministração dos conteúdos. Portanto, os duplos excepcionais precisam tanto de complementação para seus déficits, por meio do atendimento educacional especializado, quanto de suplementação para as altas habilidades com enriquecimento curricular.

\section{CONSIDERAÇÕES FINAIS}

Este artigo científico do tipo revisão teve como objetivo produzir um Estado da Arte sobre a temática da Dupla Excepcionalidade (D.E) em pessoas com altas habilidades com transtorno do espectro autista nível 1.

Frente às várias questões tematizadas apresentamos o seguinte problema de pesquisa: que tipos de assuntos são recorrentes nas produções acadêmicas (artigos em periódicos indexados) sobre a temática da dupla excepcionalidade com transtorno do espectro autista nível 1 nas obras em língua portuguesa? 
Para responder à questão central, elencamos duas hipóteses que procurarão dar suporte à pesquisa: a primeira é que as produções destes artigos tratam das características comuns dos possuidores do fenômeno em pauta e, a segunda é que elas dão algumas orientações sobre como lidar com o fenômeno em estudo, e isto produz um maior aporte aos professores de Educação Especial e também aos docentes da classe comum para lidarem com estes estudantes.

Quanto ao objetivo principal acreditamos tê-lo alcançado com o presente estado da arte. Consoante à questão central, nos dez periódicos aqui descritos temos a predominância de algumas características comuns apresentadas em pessoas com dupla excepcionalidade, na tentativa de responder a primeira hipótese, como: fraca capacidade de interação social, a fraca empatia ou dificuldade de ser empático, foco intenso naquilo que eles especificamente se interessam, a assincronia entre o desenvolvimento cognitivo, motor, psicomotor e o desenvolvimento social e afetivo, a memória cognitiva preservada e na maioria das vezes acima da média, e a fraca capacidade comunicacional em que se demonstra em dificuldades de iniciar e manter conversação e entender emoções e sentimentos dos outros.

À luz da teoria recorrente, tentamos responder à segunda hipótese os autores apontam a necessidade de maior foco às políticas públicas de formação continuada no sentido de capacitar os professores. Desta forma, os dados apontam para a necessidade de uma mais aprofundada formação continuada e de treinamento em serviço de qualidade. O não atendimento a estes estudantes com dupla excepcionalidade configura-se como desrespeito a seus direitos e podem causar, de acordo com a literatura específica destacada na pesquisa, prejuízos de diferentes ordens, tais como: problemas psicossociais, agravamento, de traumas e estigmas que deflagram, na prática, em evasão escolar e abandono deixando à margem esta pequena parcela da sociedade.

O estudo constatou, por meio de nossa investigação, tanto teórica quanto aplicada, que há falta de instrumentos específicos para identificação da dupla excepcionalidade com Transtorno do espectro autista nível 1 e altas habilidades/superdotação. Isto é um fator ainda limitante para um maior desenvolvimento desta área do conhecimento.

A identificação e a intervenção precoce das características de superdotação e dos transtornos do estudante, no contexto familiar e escolar fortalecem o desenvolvimento de suas habilidades superiores e de seus talentos. Assim, corroborando com os achados desta pesquisa, reiteramos a necessidade de pesquisas também sobre intervenção precoce com 
as crianças nas creches e pré-escola. Deste modo, sugerimos que outros estudos transversais e longitudinais sejam conduzidos para o avanço desta temática,

Uma grande lacuna neste campo de pesquisa precisa ser suprida por pesquisadores, especialmente por meio de pesquisas empíricas, com maior número de participantes envolvidos, isto pode gerar um dado muito importante para a formulação de políticas públicas no campo de atendimento a este segmento de da educação especial.

Não tivemos a pretensão de que nosso trabalho esgotou toda temática, mas acreditamos que, embora este estudo ainda se apresente como algo inacabado, no entanto poderá servir de instrumento que estimule os pesquisadores desta área do conhecimento a fazerem mais pesquisas sobre o assunto e que esta pesquisa venha a servir de inspiração para novos pesquisadores sobre a temática da dupla excepcionalidade.

\section{REFERÊNCIAS}

ALVES, Rauni Jandé Roama; NAKANO, Tatiana de Cássia. A dupla-excepcionalidade: relações entre altas habilidades/superdotação com a síndrome de Asperger, transtorno de déficit de atenção e hiperatividade e transtornos de aprendizagem. Revista

Psicopedagogia - ABPp, São Paulo, v.10, n. 99, p. 346-360, 2015. Disponível em: https://www.researchgate.net/publication/317474861_A_duplaexcepcionalidade_relacoes_entre_altas_habilidadessuperdotacao_com_a_sindrome_de_ Asperger_transtorno_de_deficit_de_atencao_e_hiperatividade_e_transtornos_de_aprend izagem. Acesso em: 20 ago. 2021.

BARDIN, Laurence. Análise de conteúdo. São Paulo: Edições 70, 2011. 229p.

COUTINHO-SOUTO, Waleska Karinne Soares e FLEITH, Denise de Souza. Inclusão educacional: estudo de caso de um aluno com dupla excepcionalidade. Revista de Psicologia, Vol. 39 (1), 2021, pp. 339-381 Disponível em: https://revistas.pucp.edu.pe/index.php/psicologia/article/view/23121/22108. Acesso em: 22 ago. 2021

FERREIRA, Norma Sandra de Almeida. As pesquisas denominadas "estado da arte". Educação \& Sociedade, São Paulo, ano 23, n. 79, p. 257-272, ago. 2002.

GUIMARÃES, Tânia Gonzaga; ALENCAR, Eunice Maria Lima Soriano de. Dupla excepcionalidade superdotação e transtorno de Asperger: contribuições teóricas.

Revista AMAzônica, Manaus, ano 5, v. X, n. 3, p. 95-108, jul./dez. 2012. Disponível em: https://dialnet.unirioja.es/servlet/articulo?codigo=4047470. Acesso em: 15 jun. 2021.

MASSUDA, Mayra Berto; RANGNI, Rosemeire de Araújo. Altas Habilidades ou superdotação e dupla excepcionalidade: definições e reflexões. In: MASSUDA, Mayra 
Berto; RANGNI, Rosemeire de Araújo; COSTA, Maria da Piedade Resende da. Altas Habilidades/Superdotação: temas para debate. São Carlos: EDUFSCAR, 2017. p. 90125.

OUROFINO, V. T. A. T.; FLEITH, D. S.; GONÇALVES, F. C. Fatores associados à baixa performance acadêmica de alunos superdotados. Psicologia em Pesquisa, Juiz de Fora, v. 5, n. 1, p. 28-38, ago. 2011. Disponível em:

http://pepsic.bvsalud.org/scielo.php?script=sci_arttext\&pid=S198212472011000100004 Acesso em: 25. Ago. 2021

RAMOS, Sheila Debastiani; HERNANDEZ, Aline Calvo. Dilemas em Educação Inclusiva: problematizações em torno às crianças com altas habilidades/Asperger.

Revista Educação, Artes e Inclusão, Florianópolis, v. 15, n. 1, p. 195-216, jan./mar. 2019. DOI: http://dx.doi.org/10.5965/1984317815012019195. Disponível em: https://www.revistas.udesc.br/index.php/arteinclusao/article/view/10207. Acesso em: 22 jun. 2020.

SILVA, Francisca Jocineide da Costa; CARVALHO, Maria Eulina Pessoa de. O Estado da Arte e as Pesquisas Educacionais Sobre Gênero e Educação Infantil: uma introdução. Anais do $18^{\circ}$ REDOR, Recife, p. 346-362, 2014.

SILVA, Sarah Carolina Furucho; RANGNI, Rosemeire de Araújo. Indicadores de altas habilidades superdotação em aluno com síndrome de asperger: estudo de caso. ECCOS - Revista Científica, São Paulo, n. 51, e8334, out./dez. 2019. DOI:

https://doi.org/10.5585/eccos.n51.8334. Disponível em:

https://www.researchgate.net/publication/338674174_Indicadores_de_altas_habilidades superdotacao_em_aluno_com_sindrome_de_asperger_um_estudo_de_caso. Acesso em: 20 set. 2021.

SIMÕES, Luís; PEREIRA, Marcelino; OLIVEIRA, Guiomar. Síndrome de Asperger e Sobredotação Intelectual: análise diferencial. Revista Sobredotação - Aneis, v. 13, p. 136-137, 2013. Disponível em:

https://www.researchgate.net/publication/328394018_Sindroma_de_Asperger_e_sobred otacao_Intelectual_Analise_diferencial. Acesso em: 18 ago. 2021.

SOARES, Larissa de Sousa; OLIVEIRA, Geane Silva. Síndrome de Asperger: manifestações clínicas e sua relação com a dupla-excepcionalidade. Revista

Interdisciplinar em Saúde, Cajazeiras, v. 7, p. 551-562, 2020. DOI:

https://doi.org/10.35621/23587490.v7.n1.p551-562. Disponível em:

http://www.interdisciplinaremsaude.com.br/Volume_28/Trabalho_42_2020.pdf. Acesso em: 20 jun. 2021.

VIEIRA, Nara Joyce Wellausen; SIMON, Karolina Waechter. Diferenças e semelhanças na dupla necessidade educacional especial: altas habilidades/superdotação x Síndrome de Asperger. Revista Educação Especial, Santa Maria, v. 25, n. 43, p. 319332, maio/ago. 2012. Disponível em:

https://www.researchgate.net/publication/279490283_Diferencas_e_semelhancas_na_d upla_necessidade_educacional_especial_altas_habilidadessuperdotacao_x_Sindrome_d e_Asperger. Acesso em: 25 set. 2021. 
VILARINHO-REZENDE, Daniela; FLEITH, Denise de Souza; ALENCAR, Eunice Maria Lima Soriano de. Desafios no diagnóstico de dupla excepcionalidade: um estudo de caso. Revista de Psicología, Lima, v. 34, n. 1, p. 61-84, 2016. Disponível em: http://www.scielo.org.pe/scielo.php?script=sci_arttext\&pid=S025492472016000100004\&lng=es\&nrm=iso. Acesso em: 24 jun. 2021.

Recebido em: 03/01/2022

Aprovado em: 25/01/2022

Publicado em: 28/01/2022 